\title{
The role of the renal biopsy and surveillance in the management of small renal masses
}

\author{
Fabio Muttin ${ }^{1}$, Eric Barret ${ }^{2}$ \\ 'Unit of Urology, Division of Experimental Oncology, Urological Research Institute (URI), IRCCS San Raffaele Scientific \\ Institute, Vita-Salute San Raffaele University, 20132 Milano, Italy. \\ ${ }^{2}$ Department of Urology, Institut Mutualiste Montsouris, Paris 75014, France.
}

Correspondence to: Dr. Eric Barret, Department of Urology, Institut Mutualiste Montsouris, Paris 75014, France.

E-mail: eric.barret@imm.fr

How to cite this article: Muttin F, Barret E. The role of the renal biopsy and surveillance in the management of small renal masses. Mini-invasive Surg 2019;3:10. http://dx.doi.org/10.20517/2574-1225.2018.005

Received: 30 Nov 2018 First Decision: 14 Jan 2019 Revised: 7 Mar 2019 Accepted: 11 Mar 2019 Published: 17 Apr 2019

Science Editor: Richard Lawrence John Naspro Copy Editor: Cai-Hong Wang Production Editor: Huan-Liang Wu

\begin{abstract}
Cross-sectional imaging shows a limited diagnostic accuracy for the histological discrimination of small renal masses (SRM). In this scenario, a renal tumor biopsy is a safe, feasible and effective diagnostic tool that can guide treatment strategy by providing the histological characterization of a SRM. Although nephron-sparing surgery is still considered the gold standard treatment for patients with SRM, more and more evidence suggests that active surveillance (AS) is a reasonable alternative option, especially in old and comorbid patients. Indeed, owing to the relatively slow growth and favorable biology of SRM, AS followed up by, if necessary, a delayed intervention provides an optimal oncological outcome with low rates of systemic progression or death.
\end{abstract}

Keywords: Small renal masses, cross-sectional imaging, renal biopsy, surveillance

\section{INTRODUCTION}

Traditionally, kidney cancer is one of the few tumors that is only treated if there is a radiological probability of malignancy. This concern is related to the limited diagnostic accuracy of computed tomography and magnetic resonance imaging in the histologic characterization of small renal masses (SRM $)^{[1]}$. In recent years, a percutaneous renal tumor biopsy (RTB) has emerged as a promising diagnostic tool that may help in the clinical decision-making process by distinguishing benign from malignant radiological inconclusive renal lesions, and thus may be considered suitable for patients who are candidates for either active surveillance or nephron-sparing treatments ${ }^{[1-3]}$.

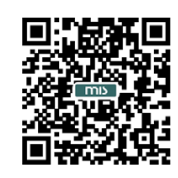




\section{Renal tumor biopsy}

In the context of SRM, RTB has been used to identify low- and high-risk malignant renal tumors, to reveal a suspected metastasis in a non-renal neoplasm, to exclude lymphoma or abscess or, when an ablative therapy (e.g., radiofrequency ablation) is planned, to obtain the histology or to confirm the success of the treatment ${ }^{[4]}$. Contraindications include comorbid and frail patients only suitable for conservative management irrespective of biopsy results; patients with coagulation impairment; patients with a contrastenhanced renal mass for whom surgery is already planned ${ }^{[1,4]}$.

According to a patient's habits, anatomical tumor location and personal experience, ultrasounds and computed tomography are conventionally used for guidance when RTBs are performed. Tissue sampling can be realized with fine needle aspiration (FNA) and/or core biopsy $(\mathrm{CB})^{[1,4]}$. In FNA, a twenty-one-gauge needle is inserted through a coaxial sheath to obtain multiple cytologic samples while limiting discomfort and the risk of tumor seeding. For $\mathrm{CB}$, an eighteen-gauge needle with the same coaxial technique provides better diagnostic samples when at least $10 \mathrm{~mm}$ long cores are taken from the central and peripheral zones while avoiding necrotic areas.

In a recent systematic review and meta-analysis, CBs have been found to have a better diagnostic accuracy for the detection of malignancy compared to FNA, with a sensitivity of $99.1 \% v$ s. $93.2 \%$ and a specificity of $99.7 \%$ vs. $89.8 \%$, respectively ${ }^{[3]}$. Higher diagnostic accuracy is reached when large solid exophytic lesions are biopsied or when a combination of the two techniques is performed ${ }^{[1,2]}$. A non-diagnostic result can occur in up to $8 \%-14.7 \%$ of all RTB (range $0 \%-22.6 \%$ for CB and $0 \%-36 \%$ for FNA). However, a repeated biopsy is diagnostic in $>90 \%$ of cases. After surgical resection, the positive and negative predictive values of RTB are $>99 \%$ and $70 \%$, respectively ${ }^{[2,3,5,6]}$. When focusing on SRM only, RTB shows a sensitivity of $99.7 \%$ and a specificity of $98.2 \%$. Furthermore, after surgical resection of SRM only, the concordance rate for tumor histotype is $96 \%$ while the concordance rate for tumor grade is $66.7 \%$ and increases to $86.5 \%$ when a simplified low-high grading system is used ${ }^{[3]}$.

Overall, RTB is feasible and safe when the coaxial technique is used. Morbidity after percutaneous sampling is low (8.1\%) and complications include spontaneous resolving subcapsular/perinephric hematoma (4.3\%$4.9 \%)$, clinically significant pain (1.2\%-3\%), self-limiting hematuria ( $1 \%-3.15 \%)$, pneumothorax (0.6\%), hemorrhage requiring blood transfusions $(0.4 \%-0.7 \%)$ and infections. Fewer than $1 \%$ of the patients experience major complications such as a gross hematuria or a pseudoaneurysm that requires embolization. Anecdotal cases are reported for tumor seeding along the needle tract ${ }^{[3,5]}$.

\section{Active surveillance}

Active surveillance (AS) is defined as the initial monitoring of tumor size by serial abdominal ultrasounds or cross-sectional imaging with delayed treatment (DT) reserved for those patients whose SRMs show clinical progression during the follow-up examination ${ }^{[1]}$. Indications for AS are still controversial, thought an elderly patient with a high surgical risk or competing risks of death and a very small low-growing renal mass represents the optimal candidate for AS [Table 1]. A recent systematic review of the oncological outcomes of currently published AS data indicates this treatment modality is a safe initial management strategy for SRM, especially for patients with very small tumors $(<2 \mathrm{~cm})$ and elderly and/or sicker patients ( $>75$ years), followed by DT only if required because of progression. Specifically, metastatic progression and cancer-specific mortality (CSM) rates for cT1a tumors have been found to be low, accounting for 0-6\% and $1 \%$, respectively. Conversely, the other-cause mortality (OCM) rate is $1 \%-45 \%$, reflecting the advanced age and prevalence of comorbidities in these AS patients $\mathrm{AS}^{[7]}$.

The data supporting these findings are manifold. Up to 52\% of all resected SRM are suitable for AS, with $23 \%$ of benign histology and $29 \%$ of favorable risk or intermediate risk $<2 \mathrm{~cm}_{\text {tumors }}{ }^{[8]}$. Moreover, a significant proportion of SRM which satisfy the criteria of AS are benign tumors or low-grade renal cell 
Table 1. Factors favoring active surveillance

\begin{tabular}{ll}
\hline Patient-related & Tumor-related \\
\hline Elderly & Tumor size $<3 \mathrm{~cm}$ \\
Life expectancy $<5$ years & Tumor growth $<5 \mathrm{~mm} /$ year \\
High comorbidities & Non-infiltrative on imaging \\
Excessive perioperative risk & Low complexity \\
Frailty (poor functional status) & Favorable histology (if RTB is performed) \\
Patient preference for AS & \\
Marginal renal function & \\
\hline
\end{tabular}

RTB: renal tumor biopsy; AS: active surveillance

carcinoma, with relatively indolent biologic and clinical behavior ${ }^{[9,10]}$. Indeed, most of SRM grow slowly, with a median linear growth rate (LGR) of $0.22 \mathrm{~cm} /$ year for $\mathrm{CT}^{\mathrm{T}} \mathrm{a}$ tumors ${ }^{[7]}$. Conversely, although benign tumors may grow significantly, high median LGR $(0.37 \mathrm{~cm} /$ year $)$ has been associated with a progression to metastasis and may be mirror more aggressive cancers ${ }^{[7,9,11,12]}$.

Elderly and comorbid patients with SRM have a relative low risk of CSM but a significant risk of OCM, thus questioning their eligibility for surgery, which may also expose the patient to a greater risk of postoperative morbidity ${ }^{[13-17]}$. In comparative retrospective and prospective analyses, although patients in the AS arm were older with greater comorbidity and smaller tumors with respect to the surgical counterpart, no statistically significant difference in OS and CSS were observed once adjusted for patients and tumor characteristics $^{[10,13,18,19]}$.

Triggers for AS cessation and commencement of treatment are poorly understood and include tumor volume doubling time $<12$ months, LGR $>0.5 \mathrm{~cm} /$ year, tumor maximal diameter at risk of systemic dissemination (3-4 cm), malignant RTB results, new onset of tumor-related symptoms and/or patient's preference ${ }^{[11,20]}$. Up to one-third of patients in AS cross over to treatment and most of them within the first $2-3$ years ${ }^{[1,2]}$. For the $1 \%-26 \%$ of $\mathrm{cT} 1$ a tumors undergoing surgical DT, the median LGR has been found $0.62 \mathrm{~cm} /$ year $^{[7]}$. Furthermore, increasing growth kinetics at the first follow-up imaging appear to be associated with higher treatment crossing over but not with OS, which suggests that rapidly growing masses early in AS may not necessarily require immediate treatment ${ }^{[12]}$.

The optimal follow-up schedule for patients in AS is still unknown and therefore hasn't been standardized. Current recommendations suggest imaging at relatively frequent intervals initially, which may increase as the stability of the lesion is demonstrated: cross-sectional imaging every 3-4 months for the first year, followed by cross-sectional imaging or ultrasound every 4-6 months for the second year and every 6-12 months thereafter ${ }^{[20]}$.

\section{Nephron-sparing surgery}

Although AS and ablative therapies have been regarded as attractive treatment modalities, partial nephrectomy (PN) represents the standard of care for the management of SRMs ${ }^{[1,15,21-23]}$. Indeed, PN has demonstrated comparable cancer control ${ }^{[24-26]}$ but a lower incidence of chronic kidney disease ${ }^{[27-30]}$, cardiovascular events ${ }^{[31,32]}$, overall and competing-cause mortality ${ }^{[31,33-35]}$ when compared to radical nephrectomy.

According to a surgeon's experience and preference, a PN can be performed with open (OPN), laparoscopic (LPN) or robot-assisted (RAPN) approach ${ }^{[1]}$. Specifically, RAPN provides non-inferior oncological and functional outcomes and an improved morbidity profile with respect to OPN ${ }^{[36,37]}$. Moreover, RAPN is now considered the preferable minimally invasive approach to PN because it eliminates the technical issues of LPN and reduces the surgical learning curve $\mathrm{e}^{[38-40]}$. 


\section{CONCLUSION}

An accurate diagnosis of SRM can be made by using RTB and will further improve the risk-stratification of patients and guide the treatment strategy. Moreover, AS is a viable alternative to standard PN for SRM and should be discussed with candidates for active intervention, according to the baseline health status and the characteristics of the tumor provided by the RTB.

\section{DECLARATIONS}

\section{Authors' contributions}

Data analysis and interpretation, manuscript writing and editing: Muttin F

Conception and design of the study, supervision and critical revision for important intellectual content: Barret E

\section{Availability of data and materials}

Not applicable.

\section{Financial support and sponsorship}

None.

\section{Conflicts of interest}

Both authors declared that there are no conflicts of interest.

\section{Ethical approval and consent to participate}

Not applicable.

\section{Consent for publication}

Not applicable

\section{Copyright}

(c) The Author(s) 2019.

\section{REFERENCES}

1. Ljungberg B, Albiges L, Abu-Ghanem Y, Bensalah K, Dabestani S, et al. European association of urology guidelines on renal cell carcinoma: the 2019 update. Eur Urol 2019; doi:10.1016/j.eururo.2019.02.011.

2. Richard PO, Jewett MAS, Bhatt JR, Kachura JR, Evans AJ, et al. Renal tumor biopsy for small renal masses: a single-center 13-year experience. Eur Urol 2015;68:1007-13.

3. Marconi L, Dabestani S, Lam TB, Hofmann F, Stewart F, et al. Systematic review and meta-analysis of diagnostic accuracy of percutaneous renal tumour biopsy. Eur Urol 2016;69:660-73.

4. Herrera-Caceres JO, Finelli A, Jewett MAS. Renal tumor biopsy: indicators, technique, safety, accuracy results, and impact on treatment decision management. World J Urol 2018;362:624.

5. Patel HD, Johnson MH, Pierorazio PM, Sozio SM, Sharma R, et al. Diagnostic accuracy and risks of biopsy in the diagnosis of a renal mass suspicious for localized renal cell carcinoma: systematic review of the literature. J Urol 2016;195:1340-7.

6. Richard PO, Jewett MAS, Tanguay S, Saarela O, Liu ZA, et al. Safety, reliability and accuracy of small renal tumour biopsies: results from a multi-institution registry. BJU Int 2017;119:543-9.

7. Mir MC, Capitanio U, Bertolo R, Ouzaid IP, Salagierski M, et al. Role of active surveillance for localized small renal masses. Eur Urol Oncol 2018;1:177-87.

8. Rahbar H, Bhayani S, Stifelman M, Kaouk J, Allaf M, et al. Evaluation of renal mass biopsy risk stratification algorithm for robotic partial nephrectomy--could a biopsy have guided management? J Urol 2014;192:1337-42.

9. Jewett MAS, Mattar K, Basiuk J, Morash CG, Pautler SE, et al. Active surveillance of small renal masses: progression patterns of early stage kidney cancer. Eur Urol 2011;60:39-44.

10. Pierorazio PM, Johnson MH, Ball MW, Gorin MA, Trock BJ, et al. Five-year analysis of a multi-institutional prospective clinical trial of delayed intervention and surveillance for small renal masses: the DISSRM registry. Eur Urol 2015;68:408-15.

11. Smaldone MC, Kutikov A, Egleston BL, Canter DJ, Viterbo R, et al. Small renal masses progressing to metastases under active surveillance: a systematic review and pooled analysis. Cancer 2012;118:997-1006. 
12. McIntosh AG, Ristau BT, Ruth K, Jennings R, Ross E, et al. Active surveillance for localized renal masses: tumor growth, delayed intervention rates, and > 5-yr clinical outcomes. Eur Urol 2018;74:157-64.

13. Lane BR, Abouassaly R, Gao T, Weight CJ, Hernandez AV, et al. Active treatment of localized renal tumors may not impact overall survival in patients aged 75 years or older. Cancer 2010;116:3119-26.

14. Kutikov A, Egleston BL, Canter D, Smaldone MC, Wong YN, et al. Competing risks of death in patients with localized renal cell carcinoma: a comorbidity based model. J Urol 2012;188:2077-83.

15. Pierorazio PM, Johnson MH, Patel HD, Sozio SM, Sharma R, et al. Management of renal masses and localized renal cancer: systematic review and meta-analysis. J Urol 2016;196:989-99.

16. Larcher A, Fossati N, Tian Z, Boehm K, Meskawi M, et al. Prediction of complications following partial nephrectomy: implications for ablative techniques candidates. Eur Urol 2016;69:676-82.

17. Larcher A, Trudeau V, Dell'Oglio P, Tian Z, Boehm K, et al. Prediction of competing mortality for decision-making between surgery or observation in elderly patients with T1 kidney cancer. Urology 2017;102:130-7.

18. Patel N, Cranston D, Akhtar MZ, George C, Jones A, et al. Active surveillance of small renal masses offers short-term oncological efficacy equivalent to radical and partial nephrectomy. BJU Int 2012;110:1270-5.

19. Alam R, Patel HD, Osumah T, Srivastava A, Gorin MA, et al. Comparative effectiveness of management options for patients with small renal masses: a prospective cohort study. BJU Int 2018;351:1296.

20. Ristau BT, Kutikov A, Uzzo RG, Smaldone MC. Active surveillance for small renal masses: when less is more. Eur Urol Focus 2016;2:660-8.

21. Motzer RJ. Kidney Cancer, Version 4.2018, NCCN Clinical Practice Guidelines in Oncology. J Natl Compr Canc Netw 2018:1-59.

22. Campbell S, Uzzo RG, Allaf ME, Bass EB, Cadeddu JA, et al. Renal mass and localized renal cancer: AUA guideline. J Urol 2017;198:520-9.

23. Finelli A, Ismaila N, Bro B, Durack J, Eggener S, et al. Management of small renal masses: american society of clinical oncology clinical practice guideline. J Clin Oncol 2017;35:668-80.

24. Zini L, Patard JJ, Capitanio U, Crépel M, la Taille De A, et al. Cancer-specific and non-cancer-related mortality rates in European patients with T1a and T1b renal cell carcinoma. BJU Int 2009;103:894-8.

25. Zini L, Patard JJ, Capitanio U, Mejean A, Villers A, et al. The use of partial nephrectomy in European tertiary care centers. Eur J Surg Oncol 2009;35:636-42.

26. Van Poppel H, Da Pozzo L, Albrecht W, Matveev V, Bono A, et al. A prospective, randomised EORTC intergroup phase 3 study comparing the oncologic outcome of elective nephron-sparing surgery and radical nephrectomy for low-stage renal cell carcinoma. Eur Urol 2011;59:543-52.

27. Sun M, Bianchi M, Hansen J, Trinh QD, Abdollah F, et al. Chronic kidney disease after nephrectomy in patients with small renal masses: a retrospective observational analysis. Eur Urol 2012;62:696-703.

28. Eckardt KU, Coresh J, Devuyst O, Johnson RJ, Köttgen A, et al. Evolving importance of kidney disease: from subspecialty to global health burden. Lancet 2013;382:158-69.

29. Scosyrev E, Messing EM, Sylvester R, Campbell S, Van Poppel H. Renal function after nephron-sparing surgery versus radical nephrectomy: results from EORTC randomized trial 30904. Eur Urol 2014;65:372-7.

30. Capitanio U, Larcher A, Terrone C, Antonelli A, Volpe A, et al. End-stage renal disease after renal surgery in patients with normal preoperative kidney function: balancing surgical strategy and individual disorders at baseline. Eur Urol 2016;70:558-61.

31. Huang WC, Elkin EB, Levey AS, Jang TL, Russo P. Partial nephrectomy versus radical nephrectomy in patients with small renal tumors--is there a difference in mortality and cardiovascular outcomes? J Urol 2009;181:55-61; discussion 61-2.

32. Capitanio U, Terrone C, Antonelli A, Minervini A, Volpe A, et al. Nephron-sparing techniques independently decrease the risk of cardiovascular events relative to radical nephrectomy in patients with a T1a-T1b renal mass and normal preoperative renal function. European Urology 2015;67:683-9.

33. Sun M, Trinh QD, Bianchi M, Hansen J, Hanna N, et al. A non-cancer-related survival benefit is associated with partial nephrectomy. Eur Urol 2012;61:725-31.

34. Kim SP, Thompson RH, Boorjian SA, Weight CJ, Han LC, et al. Comparative effectiveness for survival and renal function of partial and radical nephrectomy for localized renal tumors: a systematic review and meta-analysis. J Urol 2012;188:51-7.

35. Larcher A, Capitanio U, Terrone C, Volpe A, De Angelis P, et al. Elective nephron sparing surgery decreases other cause mortality relative to radical nephrectomy only in specific subgroups of patients with renal cell carcinoma. J Urol 2016;196:1008-13.

36. Peyronnet B, Seisen T, Oger E, Vaessen C, Grassano Y, et al. Comparison of 1800 robotic and open partial nephrectomies for renal tumors. Ann Surg Oncol 2016;23:4277-83.

37. Larcher A, Capitanio U, De Naeyer G, Fossati N, D'Hondt F, et al. Is robot-assisted surgery contraindicated in the case of partial nephrectomy for complex tumours or relevant comorbidities? A comparative analysis of morbidity, renal function, and oncologic outcomes. Eur Urol Oncol 2018;1:61-8.

38. Pierorazio PM, Patel HD, Feng T, Yohannan J, Hyams ES, et al. Robotic-assisted versus traditional laparoscopic partial nephrectomy: comparison of outcomes and evaluation of learning curve. Urology 2011;78:813-9.

39. Leow JJ, Heah NH, Chang SL, Chong YL, Png KS. Outcomes of robotic versus laparoscopic partial nephrectomy: an updated metaanalysis of 4,919 patients. J Urol 2016;196:1371-7.

40. Larcher A, Muttin F, Peyronnet B, De Naeyer G, Khene ZE, et al. The learning curve for robot-assisted partial nephrectomy: impact of surgical experience on perioperative outcomes. Eur Urol 2019;75:253-6. 